\title{
Erratum to: The aetiology of rickets-like lower limb deformities in Malawian children
}

\author{
V. S. Braithwaite ${ }^{1}$ R. Freeman ${ }^{2}$ - C. L. Greenwood ${ }^{1}$ - D. M. Summers ${ }^{3} \cdot$ S. Nigdikar $^{1}$ \\ C. B. D. Lavy ${ }^{4}$ A. C. Offiah ${ }^{5}$ N. J. Bishop ${ }^{5}$ J. Cashman ${ }^{6}$ - A. Prentice C.7 $^{1,7}$
}

Published online: 27 June 2016

(C) International Osteoporosis Foundation and National Osteoporosis Foundation 2016

\section{Erratum to: Osteoporos Int}

DOI 10.1007/s00198-016-3541-7

This article has been published as open access. Unfortunately the copyright and license terms were not indicated correctly. The correct terms are as follows:

This article may be re-used and distributed under the terms of the Creative Commons Attribution License, which permits any use, distribution, and reproduction in any medium, provided the original author(s) and the source are credited.

The copyright of the original article remains with the author(s).

The online version of the original article can be found at http://dx.doi. org/10.1007/s00198-016-3541-7.

\footnotetext{
V. S. Braithwaite

vickie.braithwaite@mrc-hnr.cam.ac.uk

1 MRC Human Nutrition Research, Elsie Widdowson Laboratory, Fulbourn Road, Cambridge, UK

2 Department of Paediatric Orthopaedics, Robert Jones Agnes Hunt NHS Foundation Trust, Oswestry, Shropshire, UK

3 Department of Surgery, University of Cambridge, Addenbrooke's Hospital, Cambridge, UK

4 Nuffield Department of Orthopaedics, Rheumatology and Musculoskeletal Science, University of Oxford, Oxford, UK

5 Department of Oncology and Metabolism, Academic Unit of Child Health, University of Sheffield, Sheffield, UK

6 Beit Cure Orthopaedic Hospital, Blantyre, Malawi

7 MRC Keneba, Keneba, The Gambia
} 